\title{
FAMÍLIA: SIGNIFICADOS ATRIBUÍDOS POR MULHERES USUÁRIAS DE UM SERVIÇO PÚBLICO DE SAÚDE
}

\author{
EXAMINING THE MEANING OF FAMILY FOR A GROUP OF WOMEN USERS \\ OF A PUBLIC HEALTH SERVICE
}

\author{
Natália Benegas Vieira ${ }^{1}$ \\ Maria de Fátima Campos Françozo ${ }^{2}$
}

\section{RESUMO}

Este estudo teve como objetivo compreender a percepção que um grupo de mulheres, usuárias do Sistema Único de Saúde (SUS) têm em relação à família, sua configuração e dinâmica. Para isso, buscou-se identificar o perfil socioeconômico e educacional das famílias, conhecer como se organizam no cotidiano familiar e a quem recorrem em situações de necessidades. Tratou-se de uma pesquisa qualitativa, realizada por meio de entrevistas semiestruturadas. Foram participantes da pesquisa 15 mães de lactentes que compareceram a um serviço de triagem auditiva neonatal em uma unidade de saúde da UNICAMP. Todas participantes assinaram o Termo de Consentimento Livre e Esclarecido. As entrevistas foram gravadas e seu conteúdo transcrito. Os dados coletados foram categorizados e analisados. Os resultados revelaram que o conceito de família não pode ser definido em apenas um termo, pois comporta diferentes significados: pertencimento, convivência, segurança, privacidade. O perfil socioeconômico das famílias apontou para uma relação entre pertencer às camadas pobres e o significado de família: esta ganha sentido, fundamentalmente, porque é ela quem socorre seus membros em situações de necessidade. A convivência familiar estabelece relações de confiabilidade que garante aos seus membros a certeza de amparo diante de contextos de dificuldades. Mais que sangue ou laços de parentesco, o sentido de segurança e pertencimento advindo desses tipos particulares de relacionamento, constitui um traço essencial no conceito de família. Os relatos mostram que apesar de os homens compartilharem tarefas domésticas e familiares, as mulheres ainda são as principais responsáveis pelo cuidado, rotina e organização do lar, mesmo quando estão empregadas. Pensar a família pela ótica delas próprias, pode indicar novas pistas para o trabalho de profissionais inseridos nos contextos do cuidado em saúde, onde a família é sempre a primeira acionada na participação dos processos de recuperação ou reabilitação.

PALAVRAS-CHAVE: Família. Relações Familiares. Características da Família. Saúde.

\section{ABSTRACT}

This study aimed at understanding the meaning of family for a group of women and users of a health service of a public university. We examined the families' social, economic and educational profile and we looked into how they organize their everyday live and to whom they

\footnotetext{
${ }^{1}$ Assistente Social, Mestranda pelo Programa de Pós-Graduação em Saúde, Interdisciplinaridade e Reabilitação, Centro de Estudos e Pesquisas em Reabilitação (CEPRE), Faculdade de Ciências Médicas, UNICAMP. Telefone: 19 991043198. E-mail: n_benegas@yahoo.com.br.

2 Assistente Social, Doutora em Saúde Mental pela UNICAMP. Departamento de Desenvolvimento Humano e Reabilitação e Centro de Estudos e Pesquisas em Reabilitação Prof. Dr. Gabriel Porto, Faculdade de Ciências Médicas, UNICAMP.E-mail: mfcf@fcm.unicamp.br.
} 
ask for help during moments of need. Qualitative methodology was carried out, using semistructured interviews to collect data. The participants were fifteen mothers who came to a program of neonatal hearing screening at UNICAMP. All participants signed the Ethical Consent. The interviews were recorded, transcribed and a content analysis model was employed to analyze the data. As part of the results, this research revealed the participants' multiple understandings of the concept of 'family': belonging, sharing, protection, privacy. Their socio economical profile showed they belong to poor segments of the population and as such, a central meaning of family relates to those individuals or groups of people whom they can count on. More than blood or kinship ties, the sense of security and belonging provided by particular types of relationships constitute an essential feature of the concept of family. This research also showed that according to the perception of the participants, family relationships assure its members that they will get support during difficult situations. The results also showed that the man is increasing his participation in domestic and family duties. But, the woman still is the one responsible for caring for the members as well as for home organization, even when she has a job. To think about family considering the point-of-view of the communities provides clues to professionals who work in the area of health care. In this context, the family is always requested to participate in the treatment or in the rehabilitation process and therefore, it is essential to take into consideration their own perception of the topic.

KEYWORDS: Family. Family Relationships. Family Characteristics. Health.

\section{INTRODUÇÃO}

Quando se pensa em entender a família, buscamos inicialmente compreender seu conceito e como ela se constitui. É possível encontrar um leque de conceitos de diversas épocas e lugares, escritos pelos mais variados autores e áreas de estudo. Contudo, nosso enfoque é na constituição da família brasileira.

Estudos recentes como de Gois (2014, p. 197), apontam que "pensar as famílias como unidades de convivência implica compreender que convivência social, incluindo a familiar, abarca o contexto das relações daquela sociedade naquele momento histórico”, portanto, é neste sentido que este estudo buscou conhecer a família, em meio às mudanças histórico-culturais que influenciam diretamente na dinâmica familiar e nos novos papéis de seus membros, compondo os diversos modelos das famílias atuais.

É comum associarmos família ao conceito que Prado (1991) traz em seus estudos, que significa, no sentido popular, pessoas aparentadas que vivem na mesma casa, particularmente o pai, a mãe e os filhos, a chamada família nuclear ou 'normal'. Porém, os tipos de família variam muito e, apesar de suas modificações, manifestam até hoje uma grande capacidade de sobrevivência e adaptação.

Para autores como Kaloustian e Ferrari (1994), a família representa um espaço privilegiado de socialização, de tolerância e divisão das responsabilidades e de busca coletiva pela sobrevivência, além de espaço de desenvolvimento e de proteção integral 
dos filhos e demais membros, oferecendo suporte afetivo e material necessários. É na família que valores éticos, laços de solidariedade e valores culturais são absorvidos, deixando marcas nas gerações.

Os estudos de Samara (1998) destacam que a família é uma instituição social fundamental e que dela dependem outras instituições. Suas pesquisam revelam que no Brasil colonial a família extensa já se fazia presente, tendo um núcleo conjugal, sendo o homem dono das riquezas, da terra e da casa grande, de modo que diversos indivíduos ligados a ele por laços de parentesco, amizade e trabalho, bem como filhos ilegítimos e agregados e escravos, compunham essa forma de organização. Esse tipo de configuração familiar era essencial à época, já que as funções econômico-sociais do local em quem viviam dependiam exclusivamente dela para subsistência.

Suas pesquisas ressaltam ainda que a família brasileira é resultado da adaptação da família portuguesa ao nosso ambiente colonial, que consigo trouxe características patriarcais e conservadoras. No entanto, essa configuração de família existiu em algumas regiões do país, mas em outras, já se apresentavam também, famílias nucleares, com pequeno número de filhos. São dados que permitem observar que, em se tratando de modelos de famílias, no Brasil nunca houve apenas um modelo.

Segundo Neder (1994), a partir da Proclamação da República, em 1889, o país passou por uma profunda modernização, envolvendo o fim do trabalho escravo e início da urbanização e industrialização, transferindo os polos econômicos e decisões políticas para o centro-sul do Brasil e, inclusive, a consolidação da ordem burguesa. Ainda conforme a autora, foram estas transformações que deram origem à família moderna e nuclear, o modelo burguês.

Neste sentido, pesquisas de Vaitsman (1994) mostram que além de passar pela questão da propriedade, a questão de gênero surge, estabelecendo distinções nas relações sociais. A família perdeu seu caráter produtivo, que produzia para seu sustento e se tornou espaço privado. O produtivo designava-se apenas ao homem, através do trabalho, e o trabalho ‘improdutivo’, à mulher, através da casa.

Vaitsman (1994) relata que a família passou a ser centrada nos filhos e o papel da mãe na representação do amor moderno e materno, dominada pelo homem e privada das atividades políticas, educacionais, culturais e científicas. Assim, a mulher deveria ser "educada para desempenhar o papel de mãe [...] e de suporte do homem para que este pudesse enfrentar a labuta do trabalho fora de casa” (NEDER, 1994, p. 31). 
Vaitsman (1994) afirma que foi em meados dos anos 50, com a crescente industrialização e urbanização, que se disseminou o conceito de igualdade, de forma que as mulheres com mais condições de acesso passaram a participar de carreiras tipicamente femininas: enfermagem, pedagogia, magistério, etc. Essa situação dá início às mudanças nas relações familiares.

A partir de então, o panorama que se pode traçar é de que no final dos anos 60, apoiada pelos movimentos sociais, a sociedade ocidental em geral passou a questionar e a desafiar a ordem burguesa, suscitando o debate e a crítica sobre seu modelo de costumes e práticas patriarcais e hierárquicas, exigindo, principalmente, o reconhecimento das mulheres como sujeito, como indivíduo (VAITSMAN, 1994).

As transformações em curso, logo influenciaram a dinâmica da família. Sarti (2010) em suas pesquisas destaca que as mudanças mais significativas nas famílias decorreram do avanço das tecnologias sobre reprodução humana, especialmente, a pílula anticoncepcional. Para a autora, esse evento interferiu decisivamente na sexualidade da mulher, oferecendo a ela a possibilidade de 'escolha', de ter ou não filhos e inclusive, separou sexualidade de maternidade, conferindo também, igualdade sexual.

Neste sentido, acrescentam-se ainda as mudanças em relação à paternidade, que passou a ser reivindicada através das solicitações de exames de DNA, que para Sarti (2010), introduziu uma tensão no papel masculino dentro da família, porém atribuindo um recurso de proteção à mulher e a criança.

Goldani (1994) em seus estudos relata que a partir dos anos 80 houve outras mudanças complexas na vida das famílias, marcada pela tendência da diminuição no tamanho e maior diversidade quanto aos seus arranjos domésticos. A autora ressalta que o número de famílias reconstituídas cresceu, resultado de separações, divórcios e recasamentos, bem como aumentou adultos vivendo só, como as famílias monoparentais.

Marca-se nesse período ainda outra mudança: esposas e filhos passam a "participar mais intensamente nas atividades de mercado de trabalho e na renda monetária familiar, compartilhando com o chefe as responsabilidades na manutenção da família” (GOLDANI, 1994, p. 8).

Para Goldani (1994), o pano de fundo dessas transformações é a falência do Estado de Bem-Estar Social, tendo como resultado a transferência de responsabilidades 
do Estado para a comunidade e a família, que passa a criar estratégias para enfrentar a crise e a ampliar as redes de solidariedade para além dos laços de parentesco.

A partir dos anos 90, Goldani (1994) ressalta que as mudanças na dinâmica demográfica do país surgem como outro elemento complicador nas relações familiares, que se trata da rápida queda das taxas de fecundidade e do aumento da expectativa de vida da população, impactando na faixa etária e longevidade dos brasileiros.

A autora ainda salienta que esse perfil demográfico causou transformações nos papéis e responsabilidades familiares, de modo que os indivíduos, em geral, passam mais tempo com sua segunda família, com quem casaram, do que com sua família de origem. Para a autora, as mulheres pobres e negras são as que mais sofrem estas modificações, pois geralmente, em processos de divórcios, ficam com os filhos e passam a chefiar a casa.

Para Gueiros (2002), todas estas importantes transformações foram incorporadas pela Carta Constitucional de 1988, principalmente quando passa a aceitar os novos arranjos familiares que surgiram e a condição do homem ou da mulher tornarem-se chefes de família.

Conforme Gueiros (2010), a família, atualmente, remete ao relacionamento entre pessoas, que não necessariamente compartilham o mesmo domicílio ou laços sanguíneos e de parentesco. A autora ressalta que hoje, principalmente em camadas populares, vem crescendo a organização em rede, em que as pessoas da comunidade/vizinhança criam laços em prol da sobrevivência.

A autora chama a atenção para a questão de que essas formas de organizações, especialmente quando se trata de filhos, situação comum em uma rede, onde a vizinhança se responsabiliza no cuidado das crianças daquele espaço, surge o fato de como estas famílias podem ser assumidas e legitimadas pelas instituições, principalmente do plano jurídico, que impõe a legalização das responsabilidades e, muitas vezes, não compreende essas estratégias de sobrevivência da população e da própria convivência familiar e comunitária.

Para Trad (2010), as famílias, hoje, tornaram-se mais flexíveis e menos hierarquizadas, o que não quer dizer que há ausência de conflitos e disputas de poder. A autora ainda toca num ponto fundamental, que mesmo com todas estas modificações em curso, recomenda-se cautela ao proclamar o fim da família nuclear, não se tratando a respeito de sua manutenção apenas, mas compreendendo que ela é resultado do 
'significado simbólico que lhe foi atribuído', sendo um referencial ou ideal de vida doméstica para a maioria da população.

Muito pertinentes são as análises de Sarti (2010) sobre a noção de família para pessoas de camadas pobres, sendo que para elas a noção de família não se designa apenas àqueles que convivem ou conviveram, mas está ligada a uma noção mais ampla e extensa da família, que "corresponde à da rede de obrigações: são da família aqueles com quem se pode contar, quer dizer, aqueles em que se pode confiar” (SARTI, 2010, p. 33).

Sarti (2004) afirma que para os profissionais que trabalham com famílias exigese um esforço ao lidar com esta questão, sobretudo, porque tendemos a confundir família com a nossa família, esquecendo de que são diferentes de nossas próprias referências culturais e sociais. Para a autora, cada família constrói sua própria história e seu próprio mito, desencadeando significados e explicação da realidade e cultura vivida.

Para Sarti (2004) os profissionais da área da saúde, principalmente, tendem a ter, com base no modelo biomédico, uma noção individualizada e objetivada do corpo e da doença, esquecendo-se das relações intersubjetivas que acontecem no âmbito familiar, por isso, nem sempre tratando os indivíduos em sua totalidade, desconsiderando o processo que pode ter desencadeado determinada doença, bem como não procuram junto da família estratégias que possam levar a uma superação do quadro.

Com o intuito de conhecer e entender a realidade das famílias atuais, o presente estudo teve como objetivo compreender a percepção que um grupo de mulheres e mães, usuárias do Sistema Único de Saúde - SUS têm em relação à família, sua configuração e dinâmica, buscando conhecer qual a concepção de família para elas, identificar o perfil socioeconômico e educacional, conhecer como se organizam no cotidiano e a quem recorrem em situações de necessidades.

\section{METODOLOGIA}

Tratou-se de uma pesquisa qualitativa, uma vez que esta melhor se adequou às finalidades da investigação. Foram participantes da pesquisa 15 mulheres/mães de lactentes, usuárias de um serviço de triagem auditiva neonatal (TAN), do Centro de Estudos e Pesquisas em Reabilitação ”Prof. Dr. Gabriel O.S. Porto” (CEPRE), da Universidade Estadual de Campinas - UNICAMP. 
Foram critérios de inclusão na pesquisa: mães de lactentes que compareceram ao CEPRE para realização da TAN, que aceitaram participar da pesquisa e assinaram o Termo de Consentimento Livre e Esclarecido ${ }^{3}$. As mães foram escolhidas aleatoriamente, independente da idade, escolaridade ou número de filhos. Quanto ao critério de exclusão, considerou-se mães com deficiência cognitiva que poderia impedir o entendimento das questões realizadas.

A coleta de dados foi realizada por meio de entrevistas semiestruturadas, com uso de um roteiro de questões abertas que foi testado para a adequação das perguntas.

Além do levantamento dos dados socioeconômicos da família, as questões centraram-se nos temas relativos à concepção de família, convivência familiar, cotidiano e divisão de tarefas, e identificação de situações em que buscam ajuda.

Com a permissão das participantes, as entrevistas foram gravadas para posterior transcrição dos relatos.

Após a coleta e transcrição dos dados, foi efetuada a categorização e análise dos dados. Para tanto, foram feitas várias leituras dos conteúdos das entrevistas e então levantadas categorias de análise, conforme modelo proposto por Bardin (2010).

Para manter o anonimato das participantes, na apresentação dos resultados estas estão identificadas por letra e número, como por exemplo: E1 (entrevistada número 1).

\section{O PERFIL DAS PARTICIPANTES E SUAS FAMÍLIAS}

Para podermos conhecer o perfil das famílias das entrevistadas, foram levantados os dados socioeconômico e educacional de cada uma. As 15 mães entrevistadas estão na faixa etária entre 19 e 39 anos. A grande maioria delas convive com cônjuge, sendo 5 delas casadas, 5 vivendo em união estável e, outras 5 , são solteiras.

Quanto à escolaridade, observamos uma diversidade: temos a maioria das mães com ensino médio completo, representando 7 delas; duas possuem ensino médio incompleto; duas ensino fundamental completo; outras duas, ensino fundamental incompleto e apenas duas possuem ensino superior, sendo uma ensino superior completo e a outra, ainda incompleto.

\footnotetext{
${ }^{3}$ A pesquisa foi aprovada pelo Comitê de Ética em Pesquisa da UNICAMP, sob o parecer de número 737-441, de 22 de julho de 2014.
}

Serv. Soc. \& Saúde, Campinas, SP v.14, n. 2 (20), p. 225-244, jul./dez. 2015 ISSN 1676-6806 
Segundo os dados do IBGE (2010), o nível de instrução da população aumentou de 2000 para 2010, revelando que o percentual de pessoas sem instrução ou com o fundamental incompleto caiu de 65,1\% para 50,2\%; ao passo que o de pessoas com ensino superior completo aumentou de 4,4\% para 7,9\%, situação que se confirma neste estudo, em que há apenas duas mães com ensino fundamental incompleto e a maioria delas já concluiu o ensino médio, o que pode garantir mais oportunidades de emprego.

Oito das mães participantes referem que estão trabalhando, enquanto que 6 estão desempregadas e, uma delas, identificou-se como do lar. Podemos observar que a maioria das entrevistadas está trabalhando, o que denota as mudanças ocorridas no papel da mulher na sociedade brasileira, combinada, certamente, com o aumento da escolaridade, permitindo o acesso ao mundo do trabalho. Tais mudanças confirmam-se, através dos dados levantados pelo Censo (IBGE, 2010), que revelaram que o nível de ocupação das mulheres passou de 35,4\% em 2000 para 43,9\% em 2010.

As participantes se encontram ainda na fase de procriação, isto é, são jovens e estão no início da fase de ter filhos (5 das que tem um único filho, tem também menos de 30 anos de idade). A média de 2 filhos que a pesquisa encontrou, está próxima dos dados do último Censo do IBGE (2010) para a maioria das famílias brasileiras, que apresentou mudanças de 2000 para 2010, revelando a queda da taxa de natalidade de 20,1\%, caindo de 2,38 filhos por mulher em 2000, para 1,90 filhos por mulher em 2010.

Sobre o número de pessoas que residem na casa das participantes, constatamos que além dos filhos e cônjuge, algumas famílias são compostas por outros membros, como a mãe, sogra e irmãos morando sob o mesmo teto, a família extensa.

Em relação às características socioeconômicas das famílias, entre uma a três pessoas contribuem no montante da renda. Em 6 famílias, apenas uma pessoa é responsável pela renda, sendo este o genitor, na maioria das vezes, assim como há duas delas solteiras, que residem com apenas os filhos e são unicamente responsáveis pela renda. Estas duas últimas representam as famílias monoparentais chefiadas por mulheres, que segundo os dados do IBGE (2010), no período de 2000 a 2010, apresentou um crescimento expressivo deste modelo de família, com a pessoa responsável do sexo feminino, saltando de 22\% para 37\%. Em 4 famílias, a composição da renda é formada pela própria entrevistada junto de seu marido/companheiro e outras 4 também contam com renda de mãe, sogra ou padrasto.

Em relação ao total da renda das famílias, o valor é bem diverso, variando de 1/2 até 5 1/2 salários mínimos. A maioria das famílias (10) recebe entre 1 a $2 \frac{1}{2} 2$ salários Serv. Soc. \& Saúde, Campinas, SP v. 14, n. 2 (20), p. 225-244, jul./dez. 2015 ISSN 1676-6806 
mínimos, enquanto que outras quatro recebem entre 3 a 5 1⁄2 salários mínimos e apenas uma refere receber $1 \frac{1}{2}$ salário mínimo; desta forma, é importante ressaltar que esta última vive do trabalho informal, atuando como autônoma. A média da renda familiar das participantes é de 2 1⁄2 salários mínimos.

O Censo do IBGE (2010) traz os resultados da renda familiar per capita, sendo que, 56,3\% das famílias brasileiras possuem renda de menos de um salário mínimo per capita; 21,9\%, entre um e dois salários; 7\%, entre dois e três, seguido de 5,1\%, com mais de cinco salários mínimos per capita; 4,2\% são caracterizados como sem renda e, em último percentual, 3,6\% com renda familiar de três a cinco salários mínimos per capita. Em relação às famílias de nosso estudo, se calcularmos a renda das famílias pelo número de seus membros, veremos que a maioria delas se encontra na maior faixa, de pessoas que recebem menos de um salário mínimo per capita no Brasil, enquanto que apenas 2 famílias recebem entre um a dois salários.

\section{PERTENCIMENTO, CONVIVÊNCIA E SEGURANÇA}

Sarti (2004) aponta como importante no debate sobre a família a ideia de que é preciso buscar conhecer seu significado a partir do sentido que atribuem a ela, por quem a vive. A partir desse pressuposto, o sentido de família aqui discutido se delimita a entender como a família constrói a noção de si própria.

Quando as participantes foram questionadas sobre o que era família, pudemos perceber que são variadas as significações e as representações que atribuem a ela, representada pelas seguintes falas:

Bom, pra mim, família é uma estrutura na vida de cada pessoa. (E4) Família é tudo, né? A família é a base, se você tem uma família estruturada, você consegue ter uma profissão boa, você consegue ter uma visão do mundo diferente. [...] eu acho que se você tiver uma família estruturada, se tiver diálogo dentro da sua casa, isso daí faz com que você seja uma boa pessoa. (E7)

Família pra mim é alicerce, é tudo. Não faço nada sem eles. (E8)

Observa-se que a família é vista pelas participantes como de extrema importância, ocupando lugar de destaque em suas vidas e que, a partir do modo em que vivem em família, determina como o sujeito se constitui no mundo. Fonseca (2004) afirma que as relações familiares parecem continuar ocupando um lugar de destaque na maneira em que a maioria de nós vê e vive o mundo, tal condição confirmada pela 
pesquisa, sendo unânime entre as participantes a afirmação de que a família é prioridade em suas vidas.

Os resultados apontaram que é na família que as entrevistadas revelaram sentir verdadeira pertença, além de encontrar apoio e segurança:

É companheira, tudo o que o cê precisa na hora tá ali, pra te ajudá... [...] tão alí pra me ajudá, com qualquer coisa, independente de tudo. (E2)

Tais ideias corroboram os estudos de Macedo (1994), quando menciona exatamente estes mesmos elementos, que parecem povoar o imaginário coletivo, em que se atribui à família qualidades que se ligam ao ambiente seguro, onde se pode encontrar amor, paz, fraternidade e harmonia depois das batalhas do cotidiano. Assim, são estas relações de afeto e compromisso com o outro que caracterizam fundamentalmente a família. Ainda neste sentido, para Carvalho (2010), os vínculos sociofamiliares asseguram ao indivíduo a segurança de pertencimento social, constituindo condição objetiva e subjetiva de pertença, assim, entendemos a necessidade de os indivíduos sentirem-se seguros e acolhidos, primeiro no ambiente familiar.

Os dados nos mostraram também que a convivência aparece estritamente ligada ao significado de família, conforme a fala:

Ah, família pra mim... Eu acho que engloba tudo: pai, mãe, avô, avó, filhos... [...] Eu acho assim, é o convívio, né? [...] A família pra mim é o conviver de cada dia. É o companheirismo, é tá junto, participar dos acontecimentos, aniversários, festa de final de ano... pra mim, eu acho que isso aí é família. (E6)

A convivência compreende o morar junto, dividir as tarefas e as contas, dividir os acontecimentos cotidianos, o reunir-se para comemorar datas especiais e o cuidar de uns aos outros quando necessário, e isso também significa família. As interações dessa convivência permite-nos citar aquilo que Sarti assegura, considerando que não só de laços biológicos se define a família, “mas pelos significantes que criam os elos de sentido nas relações, sem os quais essas relações se esfacelam, precisamente pela perda, ou inexistência de sentido” (2004, p. 18).

“A família, inclusive para os adultos, continua tendo essa função de dar sentido às relações entre os indivíduos e servir de espaço de elaboração das experiências vividas” (SARTI, 2004, p. 17). Desta afirmação, podemos pressupor o porquê de as 
participantes elencarem o conviver como um importante elemento ao se considerar o que significa família para elas.

Algumas das participantes elegeram a família como a instituição primeira a quem se pode recorrer, principalmente quando passam por situações de necessidades (financeira, cuidado com os filhos), definindo assim, um dos significados de família para elas, ou seja, família é aquela que me socorre:

Olha, pra mim família é tudo. Se eu tiver que recorrer a alguém, pedir socorro pra alguém, desabafar com alguém, quem que eu vou recorrer? À minha família, pai, mãe, irmãs, eu não vou sair pra um vizinho, então é o porto seguro que a gente tem, é um pilar, é os únicos que você vai poder contar. (E10)

Sendo assim, considerando o perfil sociofamiliar das participantes, observamos que elas pertencem na grande maioria às camadas pobres, o que vai ao encontro das análises de Sarti (2010) feitas também com pessoas pertencentes a segmentos pobres da população, quando afirma que na sociedade brasileira a família tem um valor alto e central para estes sujeitos, funcionando como rede de apoio e ajuda mútua, diante do desamparo social.

Neste sentido, Sarti (2011) afirma que a noção de família define-se em torno de um eixo moral, ou seja, as relações são traçadas a partir de um princípio quase que de obrigação. De tal modo, esse eixo moral significa a obrigação/dever de ajuda ao outro, entre os membros ou não da família, que se apoia no dar, receber e contribuir contínuo, assim, cada membro espera e conta com o outro, bem como cada um tem a noção de que deve obrigação ao outro. “A pessoa ajuda quem tem precisão, na certeza de que será ajudada quando chegar a sua hora” (SARTI, 2004).

Convém ressaltar que são os membros da própria família ou da família extensa que as amparam em tais situações, por exemplo, os pais (que não moram mais junto), a sogra, a tia, etc. No entanto, as participantes relatam evitar ao máximo ter que pedir auxílios a quem quer que seja, sobretudo, por que entendem que ao formar sua própria família, necessariamente precisam dar conta de suas próprias demandas.

Uma outra dimensão levantada pelas participantes da pesquisa foi a visível separação da família como espaço privado. Os estudos de Vasconcelos apontam para a importância deste espaço da família para o sujeito:

“[...] é na família que ele experimenta uma vivência de coletividade e de liberdade. Suas decisões sobre vestuário, lazer, utilização dos recursos domésticos, escolarização dos filhos, poupança, organização 
de uma festa ou de um passeio, apesar de marcadas pela carência, se realizam como atividade livre tomada na, com e para a família, em oposição às coerções do mundo do trabalho" (VASCONCELOS, 1999, p. 9).

Neste sentido, as participantes ressaltaram que a família faz tudo aquilo que outros (público) não fazem. Uma delas fez a seguinte afirmação: “apoia você em tudo... sempre tá do lado da gente, que faz o que amigos não fazem” (E13). Mais uma vez, identifica-se o significado de família como apoio, amparo. Conforme Carvalho (2010), a família é expressão máxima da vida privada:

[...] é lugar da intimidade, construção de sentidos e expressão de sentimentos, onde se exterioriza o sofrimento psíquico que a vida de todos nós põe e repõe. É percebida como nicho afetivo e de relações necessárias à socialização dos indivíduos, que assim desenvolvem o sentido de pertença a um campo relacional iniciador de relações excludentes na própria vida em sociedade. É um campo de mediação imperdível (CARVALHO, 2010, p. 271).

Esse campo de mediação que é a família vem se transformando constantemente e conforme as participantes foram descrevendo suas famílias, diversos elementos surgiram. Muitas delas reconhecem que suas famílias não se encaixam em um padrão ideal de família, assim como, reconhecem também suas dificuldades, aceitando que os problemas fazem parte das relações sociais, como sugere esta fala:

[...] não deixa de ser família, porque eu acho que não tem família perfeita... Aos trancos e barrancos, às vezes, mas a gente é família. (E1)

Deste modo, os resultados nos levam a entender que as famílias parecem se aceitar em suas dificuldades e problemas, percebendo que tais situações são comuns às outras famílias, pois o que importa mesmo para elas está em poder contar com o outro diante de contextos adversos.

Entretanto, apesar de haver esta aceitação no que diz respeito à sua própria família, ainda assim não compreendem como a do outro pode ser diferente, seja na sua estrutura e organização, seja por não conseguirem se manter unidas diante dos conflitos e necessidades:

Olha, eu tenho achado que as famílias hoje tá pior do que antes... As famílias mesmo passando por necessidade, tinha mais união. Hoje em dia, não... Hoje em dia mudou muito... Mudou o amor mesmo... Hoje 
é pai matando filho, filho matando pai... Não é mais que nem antigamente, não. Antigamente era tudo unido. (E13)

Sendo assim, concluem que os valores familiares não existem ou não são mais como antigamente, uma visão relativamente ingênua e romantizada sobre como viviam as famílias no passado.

\section{ORGANIZAÇÃO FAMILIAR: TAREFAS, OBRIGAÇÕES E PAPEIS}

Outra situação que importa analisar é que, hoje, o viver em família também traz novas responsabilidades e (re) definições de papéis. Através dos relatos observamos que existe uma clara diferença nas autoridades do homem e da mulher. O homem ainda é identificado como elo mediador entre a família e o mundo externo, a mulher, por sua vez, representa a casa. O homem é considerado o chefe da família e a mulher, a chefe da casa; o pai, autoridade moral, a mãe, quem cuida e zela pela família (SARTI, 2004).

As relações de autoridade e poder constituem elementos ordenadores da cena doméstica, com direitos e deveres específicos para cada um: pai, mãe e filhos (TRAD, 2010). Para Heilborn (1995), no entanto, este modelo tem se transformado, já que hoje a maioria dos casais modernos se forma através da crença no sentimento amoroso e procura se estruturar sob a base do princípio da igualdade e indiferenciação entre os gêneros, o que vem permitindo reivindicar a divisão equânime das tarefas domésticas e na manutenção financeira da família.

Pelos relatos ainda vemos a maioria das famílias formadas pelo modelo nuclear e tradicional, principalmente as famílias daquelas mulheres que se encontram desempregadas:

Só tem uma mulher, então quem tem que tomar conta sô eu mesmo. Eu faço tudo, o marido fica responsável pelas conta” (E9).

Desta forma, tomam para si as obrigações referentes às tarefas domésticas e, mesmo aquelas que trabalham, ainda se mantém como donas de casa.

Uma das participantes, por exemplo, confirma a ideia de que as tarefas domésticas são obrigação da mulher: “...a parte pesada fica pra mim, porque sou eu a mulher, né?” (E12). Para Martin \& Ângelo (1999) existe uma naturalização da função 
materna do cuidado, como se ela nascesse com essa habilidade, o que pode favorecer sua incorporação irreflexiva no cotidiano das mulheres, o que parece ser comum, diante dos resultados.

Em contrapartida, em algumas famílias já podemos verificar uma divisão de papéis um pouco mais igualitária, principalmente daquelas em que as mães já trabalham fora de casa, o que nos permite dizer que é a situação em que mais se observa a participação masculina, seja envolvido nas tarefas de casa ou no cuidado com os filhos, conforme podemos observar neste relato:

Meu marido já chega na parte da noite, aí meu marido já me dá um descanso e é ele que vai fazendo mais as coisas. (E8)

Se vai levá um (filho) pro médico, os dois tá ino, tipo eu como o pai [...] ele quer acompanhar tudo, né? (E9)

À medida que se reconfigura o papel da mulher na sociedade, com a entrada no mercado de trabalho e sua maior escolaridade, redefinem-se também seu papel na família e na própria figura do casamento ou do casal (TRAD, 2010).

A figura do pai vem sofrendo mudanças nos padrões sociais, pois o ideal igualitário nas relações de gênero vem favorecendo a emergência do novo pai, este que agora quer assumir sua paternidade, entendendo-a como uma oportunidade de participar de forma ativa no cuidado com os filhos, e mais, buscando demonstrar os sentimentos paternos (TRAD, 2010).

Não obstante, a concepção de modelo de família padrão e nuclear, esteve presentes em diversos relatos das entrevistadas, em que um delas, por exemplo, revelou que ainda espera "tá casada no papel [...] tá com ele bem velhinha, o casal bem velhinho e os filho cuidano dos dois” (E2). Para Lopes (1994), existe ainda um conjunto de ideias romanticamente elaboradas sobre o outro na relação amorosa, o que é um marco determinante para a constituição e manutenção da família nuclear.

Os autores Calderón e Guimarães (1994) explicam que a idealização de família é aquela que um dia sonhamos em construir: a realização do casamento, a fantasia de constituir uma família com companheiro (a), filhos, casa e, principalmente, ser feliz por toda a vida. No entanto, por vezes essa família é muito distante da real e quem não se enquadra, está fora do padrão de “normalidade”.

Este tipo de família marca presença tão forte no imaginário coletivo, de tal forma que algumas das pesquisadas comprovam essa idealização, quando por vezes passam a julgar outras famílias que parecem não se encaixar neste padrão. Assim, essas famílias recebem o título de “desestruturadas” ou “multiproblemáticas”, termos que as Serv. Soc. \& Saúde, Campinas, SP v. 14, n. 2 (20), p. 225-244, jul./dez. 2015 ISSN 1676-6806 
vinculam apenas na "função de falência das famílias, tantos nos seus aspectos materiais como socioafetivos e, portanto, definem a família como ‘o’ problema” (MIOTO, 2010, p. 59).

Segundo Calderón e Guimarães (1994), a família envolve valores, normas e práticas, que se manifestam através do pensar e do agir dos indivíduos e que são transmitidos de geração para geração, assim, ela passa a ter um padrão cultural, fazendo com que as pessoas sejam as próprias vigilantes, destinadas a punir a violação das "normas" e "rituais".

Essa punição para os autores toma formas sutis, como os comentários maliciosos e fofocas, cujos efeitos envolvem sentimentos de culpa e agridem a individualidade, o respeito, a honra e a dignidade das pessoas. Calderón e Guimarães (1994) afirmam que esse choque de valores se manifesta através do preconceito e discriminação, ou seja, na negação de outros tipos de arranjos familiares: “Olha, lá onde eu moro, tem muitas famílias que não é tipo que nem a gente, né?” (E9), que contestam os padrões culturais existentes, pois a família ideal faz parte da nossa cultura, onde desde crianças todos aprendem como “deve” e “tem” que ser uma família, já que esse modelo é reproduzido em diversos espaços de socialização ou aparelhos ideológicos, como a escola e a igreja, por exemplo.

Apesar deste ideal de família ainda persistir, já se sabe que na prática e na realidade vivida nos deparamos com outros tipos de organização. Um dos tipos de organização encontrada dentre as participantes, foi a da mulher como arrimo e chefe de família. Trad (2010) alerta que essa função não implica, necessariamente, a criação de modelo alternativo de família, mas antes na impossibilidade de realização do modelo preferencial.

Em um dos relatos, em que a mãe é a única provedora da casa, é interessante notar que mesmo onde existe este tipo de organização, parece haver a busca em manter um modelo tradicional de família, quando diz que, mesmo tendo seu filho apenas 12 anos, ele “é o homem da casa [...] Bem ou mal, é ele” (E10).

Para Sarti (2004), o que ocorre é que existem modificações importantes quando as mulheres também assumem a responsabilidade econômica, pois a autoridade masculina passa a ser abalada quando ele não consegue ser o único provedor. E mais, quando a mulher é única provedora, tende-se a procurar outra figura masculina de autoridade na família. Para a mulher não é um problema ter que trabalhar e sustentar a casa, mas fica faltando a dimensão do respeito que é imposta pela figura masculina. Serv. Soc. \& Saúde, Campinas, SP v.14, n. 2 (20), p. 225-244, jul./dez. 2015 ISSN 1676-6806 
Conforme a autora encontrou em suas pesquisas, é sempre muito comum que o filho mais velho cumpra o papel de chefe da família.

Ainda sobre os tipos de organização das famílias, identificamos como muito comum as famílias reconstituídas, sendo estas caracterizadas como a organização familiar em que o casal, ou um de deles, possui um ou vários filhos de relação anterior.

Para as participantes, este tipo de organização tem ocorrido sem grandes complicações:

Hoje ele (companheiro) tá incluído (na família). Ele trata todos (filhos) iguais. Eu tenho um netinho, do meu filho mais velho, e ele chama de vô. Ele (companheiro) tem um carinho muito grande pelas crianças. A convivência é muito boa. (E3)

Porém, convém ressaltar que essas transformações resultam em novos modos de ser entre homens e mulheres, que terminaram por constituir novos códigos (SZYMANSKI, 2002).

Os dados revelaram uma situação comum entre todas as participantes. Questionadas sobre o que esperavam de suas famílias, a grande maioria se referiu àquilo que esperam que seus filhos possam vir a ser ou a conquistar no futuro. Para Silveira, essa é uma expectativa de todas as famílias, "pautado na crença em si mesmos, na possibilidade de ser e se ter mais na vida, na crença de que a vida pode ser mais digna e o futuro mais promissor” (SILVEIRA, 2010, p. 107). Assim sendo, percebemos que as mães projetam nos filhos a realização da ideia de que a família cumpriu seu papel:

Eu nem quero viver muito, só quero ver meus filhos encaminhados, sabe? (E12)

Um ponto importante a se entender é a preocupação que as mães têm ao pensarem que seus filhos possam vir a passar pelas mesmas situações de necessidades que elas, de tal modo que temem que se repita um ciclo de dificuldades na família. Algumas delas relataram que passaram por grandes problemas no decorrer de suas vidas: de ordem financeira, em sua maioria, abandono dos estudos para poder trabalhar, trabalho na adolescência, abandono pela família, morte de membros da família, dentre outros. É neste sentido seus relatos:

Às vezes lá atrás, teve tanta privação... então hoje em dia que você tem um pouquinho mais de conforto, você quer passar pro filho. (E10) Eu espero dá muito estudo pra eles [...] Que a gente não teve, né?(E9) 
Desta forma, elas buscam ensinar, compartilhar e transmitir um conjunto de valores aos seus filhos, para que tais situações não se repitam. Esta situação corrobora as análises de Cerveny (2001), quando explica como se dá a relação de mãe/pai com os filhos. Estes procuram transmitir rituais, rotinas, regras ou padrões de cuidado, de uma geração para a outra, como estratégia de preservação do grupo, de tal forma que, diante das transformações no ambiente externo, seus filhos consigam superar determinadas situações.

\section{CONSIDERAÇÕES FINAIS}

As participantes revelaram que atribuem diferentes significados à família, não tendo esta uma única uma dimensão. A família representa a convivência com pessoas com quem querem dividir experiências, o afeto, a união, o amparo, o porto-seguro. Principalmente, representa o lugar aonde se vai quando situações de dificuldades aparecem, sempre na esperança de obter apoio imediato.

Observa-se que o perfil socioeconômico das famílias aponta para uma relação entre pertencer às camadas pobres e o significado de família: em situações de necessidade, recorrente nesta classe, a família ganha sentido, fundamentalmente, porque é ela quem socorre em tais situações. Nesse sentido, a convivência familiar faz com que se estabeleçam relações de confiabilidade que garante aos seus membros a certeza de amparo diante de contextos de dificuldades.

Quanto à organização das famílias, os dados revelaram que apesar de grandes mudanças, o papel de cada um de seus membros ainda é bastante demarcado, ou seja, a mulher como responsável pelo cuidado dos membros e administração da casa e o homem como autoridade e provedor. Notam-se mudanças no papel do homem na família, principalmente no que diz respeito à paternidade participativa. Por outro lado, os relatos nos mostram que apesar de os homens passarem a compartilhar mais os cuidados com as tarefas domésticas e filhos, as mulheres ainda são as principais responsáveis pelo cuidado, rotina e organização do lar, mesmo quando estão empregadas.

Tais resultados nos permitem dizer que há uma manutenção da função da família, tanto no seu papel de segurança e de apoio aos seus membros, quanto espaço de privacidade. A idealização do casamento também foi identificada. 
Sendo assim, trabalhar diretamente com famílias exige o entendimento destas mudanças, mas também o entendimento da manutenção de seus papéis e valores. Pensar a família pela ótica delas próprias, como os resultados apontaram, podem indicar novas pistas no trabalho dos profissionais, no sentido de criar estratégias no trato com as famílias, uma vez que inseridas nos contextos de saúde, em situações de doença, a família é sempre a primeira acionada na participação dos processos de recuperação ou reabilitação.

Recebido em 15.09.2015 - Aprovado em 30.10.2015

\section{REFERÊNCIAS}

BARDIN, L. Análise de Conteúdo. Edições 70, Edição Revista e Atualizada, 2010.

CALDERÓN, A. I; GUIMARÃES, R. F. “Família: a crise de um modelo hegemônico”. Serviço Social \& Sociedade, São Paulo. No 46, p. 21-34, dezembro de 1994.

CARVALHO, M. do C. B. Famílias e políticas públicas. In: ACOSTA, A. R.; VITALE, M. A. F. (Orgs). Família: redes, laços e políticas públicas. São Paulo: Cortez. Coordenadoria de Estudos e Desenvolvimento de Projetos Especiais - PUC/SP, 5. ed., p. 267-274, 2010.

CERVENY, C. A família como Modelo: desconstruindo a patologia. São Paulo: Livro Pleno, 2001.

FONSECA, C. Olhares antropológicos sobre a família contemporânea. In: ALTHOFF, C. R.; ELSEN, I.; NITSCKE, R. G. (Orgs.). Pesquisando a família: olhares contemporâneos, Florianópolis: Papa-Livro, p. 55-68; 2004.

GOIS, D. A de. Famílias: aportes teórico-metodológicos para o debate no âmbito do Serviço Social. Serviço Social \& Saúde, Campinas, SP, v. 13, n. 2 (18), p. 189-204, jul./dez., 2014. Disponível em: http://periodicos.bc.unicamp.br/ojs/index.php/sss/article/view/8634900 Acesso em: 19/02/2015 .

GOLDANI, A. M. As Famílias Brasileiras: Mudanças e Perspectivas. Cadernos de Pesquisa, São Paulo, n. 91, p. 7-22, 1994. Disponível em: www.fcc.org.br/pesquisa/publicacoes/cp/arquivos/743.pdf Acesso em: 19/02/2015.

GUEIROS, D. A. Família e proteção social: questões atuais e limites da solidariedade familiar. Serviço Social \& Sociedade, São Paulo: Cortez, ano XXIII, nº. 71, p. 102121, 2002. 
GUEIROS, D. A. Família e trabalho social: intervenções no âmbito do Serviço Social. Katálysis, Florianópolis, v. 13, n. 1, p. 126-132, 2010 Disponível em: http://www.scielo.br/pdf/rk/v13n1/15.pdf Acesso em: 20/02/2015.

HEILBORN, M. L. O que faz um casal, casal? Conjugalidade, igualitarismo e identidade sexual em camadas médias urbanas. In: RIBEIRO, I. e RIBEIRO, A. C. T. (Orgs). Família em processos contemporâneos: inovações culturais na sociedade brasileira. São Paulo: Loyola, p. 91-124, 1995.

IBGE. Censo Demográfico 2010. Disponível em: http://www.censo2010.ibge.gov.br Acesso em: 17/02/2015.

KALOUSTIAN, S. M. (Org.); FERRARI, M. Família brasileira, a base de tudo. São Paulo: Cortez, Brasília, DF: UNICEF, 1994.

LOPES, J. R. Das famílias ‘desestruturadas’ às famílias 'recombinadas': transição, intimidade e feminilidade. Serviço Social \& Sociedade, São Paulo: Cortez, Ano 15, n. 46, dez., p. 5-20, 1994.

MACEDO, R. M. A família do ponto de vista psicológico: lugar seguro para crescer? Cadernos de Pesquisa. São Paulo, n. 91, p, 62-68, nov. 1994. Disponível em: http://publicacoes.fcc.org.br/ojs/index.php/cp/article/view/877 Acesso em: 17/02/2015. MARTIN, V.B; ÂNGELO, M. A organização familiar para o cuidado dos filhos: percepção das mães em uma comunidade de baixa renda. Revista Latino-Americana de Enfermagem, Ribeirão Preto, v. 7, n. 4, outubro, p. 89-95, 1999. Disponível em: http://www.scielo.br/pdf/rlae/v7n4/13493.pdf Acesso em: 17/02/2015.

MINAYO, M. C. S. Pesquisa social: teoria, método e criatividade. Petrópolis: Vozes, 11. ed., 1999.

MIOTO, R. C. T. A Família como Referência nas Políticas Públicas: dilemas e tendências. In: BOMFIM, L. A. Trad (Org). Família Contemporânea e Saúde: significados, práticas e políticas públicas. Rio de Janeiro: FIOCRUZ, p. 51-66, 2010.

NEDER, G. Ajustando o foco das lentes: um novo olhar sobre a organização das famílias no Brasil. In: KALOUSTIAN, S. M. (Org). Família brasileira, a base de tudo. São Paulo: Cortez, Brasília, DF: UNICEF, p. 26-47, 1994.

PRADO, D. O que é Família. São Paulo: Brasiliense, $12^{\text {a }}$ Edição, 1991.

SAMARA, E. de M. A família brasileira - São Paulo: Brasiliense, 1998.

SARTI, C. A. A família como ordem simbólica. Psicologia USP. São Paulo, v. 15, n. 3, p. 11-28, 2004. Disponível em: www.scielo.br/pdf/pusp/v15n3/24603.pdf Acesso em: 26/02/2015.

Serv. Soc. \& Saúde, Campinas, SP v.14, n. 2 (20), p. 225-244, jul./dez. 2015 ISSN 1676-6806 
SARTI, C. A. Família como Universo Moral. In: A Família Como Espelho - Um Estudo Sobre a Moral dos Pobres. 7 ed. São Paulo: Cortez, p. 55-86, 2011.

SARTI, C. A. Famílias enredadas. ACOSTA, A. R.;VITALE, M. A. F. (Orgs). In: Família: redes, laços e políticas públicas. São Paulo: Cortez: Coordenadoria de Estudos e Desenvolvimento de Projetos Especiais - PUC/SP, 5. ed., p. 21-36, 2010.

SILVEIRA, A. Definindo o projeto de vida familiar: a família na transição para o cuidado domiciliar da criança com necessidades especiais. Tese de Doutorado apresentada à Escola de Enfermagem da Universidade de São Paulo, 2010. Disponível em: http://www.teses.usp.br/teses/disponiveis/7/7141/tde-25102010-152230/en.php Acesso em 19/02/2015.

SZYMANSKI, H. Viver em família como experiência de cuidado mútuo: desafios de um mundo em mudança. Serviço Social \& Sociedade, São Paulo, ano 21, n. 71, set, p. 9-25, 2002.

TRAD, L. A. B. A Família e suas Mutações: subsídios ao campo da saúde. In: Leny A. Bomfim Trad (Org.). Família Contemporânea e Saúde: significados, práticas e políticas públicas. Rio de Janeiro: Editora FIOCRUZ, p. 27-50, 2010.

TURATO, E. R. Métodos qualitativos e quantitativos na área da saúde: definições, diferenças e seus objetos de pesquisa. Revista Saúde Pública, p. 507-514, 2005. Disponível em: http://www.scielo.br/pdf/rsp/v39n3/24808.pdf Acesso em: 19/02/2015.

VAITSMAN, J. Flexíveis e plurais: identidade, casamento e família em circunstâncias pós-modernas. Rio de Janeiro: Rocco, 1994.

VASCONCELOS, E. M. A priorização da família nas políticas de saúde. Saúde em Debate, Rio de Janeiro, v. 23, n. 53, set./dez., p. 6-19, 1999. Disponível em: https://www.mp.go.gov.br/portalweb/hp/2/docs/saude25livro_saude_em_debate.pdf\#page=9 Acesso em: 19/02/2015 